\title{
BMJ Global Health 20 years of gender mainstreaming in health: lessons and reflections for the neglected tropical diseases community
}

\author{
Sally Theobald, ${ }^{1}$ Eleanor E MacPherson, ${ }^{2}$ Laura Dean, ${ }^{2}$ Julie Jacobson, ${ }^{3}$ \\ Camilla Ducker, ${ }^{4}$ Margaret Gyapong, ${ }^{5}$ Kate Hawkins, ${ }^{6}$ Thoko Elphick-Pooley, ${ }^{7}$ \\ Charles Mackenzie, ${ }^{8}$ Louise A Kelly-Hope, ${ }^{9}$ Fiona M Fleming, ${ }^{10}$ \\ Pamela S Mbabazi ${ }^{11}$
}

To cite: Theobald $\mathrm{S}$, MacPherson EE, Dean L, et al. 20 years of gender mainstreaming in health: lessons and reflections for the neglected tropical diseases community. BMJ Glob Health 2017;2:e000512. doi:10.1136/ bmjgh-2017-000512

Handling editor Seye Abimbola

Received 3 August 2017 Revised 3 0ctober 2017 Accepted 4 October 2017
CrossMark

For numbered affiliations see end of article.

\section{Correspondence to} Dr Eleanor E MacPherson; eleanor.macpherson@Istmed. ac.uk

\section{ABSTRACT}

Neglected tropical diseases (NTDs) affect the poorest of the poor. NTD programmes can and should rise to the challenge of playing a part in promoting more gender equitable societies. Gender equity shapes poverty and the experience of disease in multiple ways; yet to date, there has been little attention paid to gender equity in NTD control efforts. Drawing on a synthesis of relevant literature, the tacit knowledge and experience of the authors, and discussions at a meeting on women, girls and NTDs, this analysis paper distills five key lessons from over 20 years of gender mainstreaming in health. The paper links this learning to NTDs and Mass Drug Administration (MDA). Our first lesson is that tailored gender frameworks support gender analysis within research and programming. We present a gender review framework focusing on different MDA strategies. Second, gender interplays with other axes of inequality, such as disability and geographical location; hence, intersectionality is important for inclusive and responsive NTD programmes. Third, gender, power and positionality shape who is chosen as community drug distributors (CDDs). How CDDs interact with communities and how this interface role is valued and practised needs to be better understood. Fourth, we need to unpack the gender and power dynamics at household level to assess how this impacts MDA coverage and interactions with CDDs. Finally, we need to collect and use sex disaggregated data to support the development of more equitable and sustainable NTD programmes.

\section{INTRODUCTION}

Neglected tropical diseases (NTDs) are defined by the CDC as 'a group of parasitic and bacterial diseases that cause substantial illness for more than one billion people globally'. They affect some of the poorest and most marginalised people in the world. ${ }^{2}$ Those affected by NTDs can face life-altering morbidity, which may result in disability, and have wide-ranging economic and social consequences for individuals as well as their families. ${ }^{3}$ Poverty, poor access to safe water and limited access to health services also enhance

\section{Key questions}

What is already known about this topic?

- Neglected tropical disease (NTD) programmes have paid little attention to gender analysis.

- Frameworks to promote and implement gender mainstreaming exist but have not been applied to NTDs.

\section{What are the new findings?}

- This paper draws together gender-related lessons learnt in the past 20 years from gender mainstreaming approaches in health and applies them to NTDs.

\section{Recommendations for policy}

- We suggest practical, constructive approaches to support the development of more gender equitable NTD control programmes.

vulnerability to NTDs. ${ }^{3}$ These key structural barriers mean that communities and families living with NTDs, such as onchocerciasis and lymphatic filariasis, can remain trapped in a cycle of poverty. ${ }^{4}$

NTD programmes have been relatively successful at promoting equity by ensuring that preventive approaches and treatments are accessible through Mass Drug Administration (MDA) campaigns. ${ }^{5}$ MDA campaigns aim to ensure that all those living in affected communities have access to preventive chemotherapy through repeated school or community drug distribution. In very marginalised contexts, NTD programmes may be the only health services accessible to communities. For example, in 2015 during the Ebola outbreak, the NTD programme continued to function in some areas due to community persistence and the availability of drugs when many health services stopped (Karsor Kollie, Head of the Liberian NTD 
programme; Personal Communication; 2016). In Yemen, despite ongoing conflict, treatments for NTDs are reaching vulnerable groups ${ }^{6}$ WHO has described NTDs as the 'litmus test for universal health coverage' because they often affect the poorest and most marginalised who have poor access to healthcare. ${ }^{7}$ NTDs have also been included as an 'equity' tracer within the Sustainable Development Goals. ${ }^{8}$

Gender is a core concept in discussion and action related to equity. Gender refers to the socially constructed roles, behaviours, activities and attributes that a given society considers appropriate for men, women and other genders. These socially ascribed roles and behaviours can affect all aspects of peoples' lives including their health and well-being. ${ }^{9} 10$ Gender roles and relations can shape peoples' vulnerability to and experience of NTDs, how they experience poverty, and their ability to access care and treatment. ${ }^{11}$ Furthermore, gender can intersect with other axes of inequality such as age, nationality, ethnicity, religion, sexuality, (dis)ability and socioeconomic status. ${ }^{12}$ Who is involved in the delivery of NTD programmes at the community level and beyond, shapes how programmes are delivered and this is also influenced by gender. ${ }^{13}$ The NTD sector is working to strengthen the gender analysis that underpins its policy, programmes and data collection. This was the focus of a recent meeting (Neglected Tropical Diseases: Women and Girls in Focus, July, 2016) ${ }^{\mathrm{i}}$ that brought together donors, researchers, policy makers and practitioners from different contexts. ${ }^{14}$

The global health community has over 20 years' experience of gender mainstreaming, a concept formalised at the Beijing International Women's conference in $1995 .{ }^{15} 16$ This analysis piece draws on a synthesis of relevant literature, tacit knowledge and experience of the authors, and discussions at the Women and Girls in Focus meeting. We reflect on five key lessons learnt from the gender mainstreaming process and their implications for donors, policy makers and practitioners working in the NTD field, and highlight relevant lessons for promoting gender equity in NTD programmes. We explore this through the specific case study of MDA which has been a core prevention and treatment strategy for NTDs for several decades. We do however recognise the importance of considering gender equity in relation to other NTD interventions, such as innovative and intensified disease management, and disease management and disability and inclusion strategies in order to mainstream gender fully in NTD policy and programming.

\footnotetext{
i "Neglected Tropical Diseases: Women and Girls in Focus"; meeting held in London July 27-28. 2016 Organising committee: Camilla Ducker, DFID; Noelle Huskins, BMGF; Julie Jacobson, BMGF; Pamela Mbabazi, WHO; Amy Pennington, BMGF; Thoko Pooley, Uniting to Combat NTDs; Sarah Simpson, EquiACT.
}

Lesson 1: Tailored gender frameworks help make the focus on gender explicit

Gender frameworks can help researchers, policy makers and practitioners understand and address the gender power relations which are most relevant to their work. Morgan et $a l^{10}$ identified 42 gender frameworks, guidelines and tools developed by a variety of agencies and organisations (15 of which focus on health, health systems and development). ${ }^{10}$ The health examples included a manual for integrating gender in reproductive health and HIV programmes and a guide by Pan American Health Organization (PAHO) to organise analysis and monitoring of gender equity in health policies. ${ }^{10}$ To date, no gender mainstreaming frameworks relate specifically to NTDs, which is a missed opportunity for action.

To promote gender equity within MDA, we need to start by breaking down the different components of the intervention. MDA can be implemented in different ways depending on the context, target groups and diseases which are being treated and prevented. In table 1 , drawing on discussions at the Women and Girls in Focus meeting, we have broken down the different elements of MDA, summarised the extent to which sex disaggregated data are collected and posed questions to support critical reflection on how gender may shape access to, and experiences of, MDA. This is not an exhaustive list, and the issues and questions under discussion may not be appropriate for all settings. Gender frameworks, such as in table 1, are most effective when used as a starting point for collective thinking to develop deeper understanding and ownership of gender issues and to ensure that the questions under review are appropriately adapted to context. $^{17}$

\section{Lesson 2: Gender does not operate in isolation: taking on the challenge of intersectionality}

Gender interplays with other axes of privilege, power and inequity such as age, nationality, ethnicity, religion, sexuality, (dis)ability and socioeconomic status. ${ }^{18}$ Larson et $a l^{2}$ argue that 'Intersectionality has emerged as an important framework for understanding and responding to health inequities by making visible the fluid and interconnected structures of power that create them'. ${ }^{12}$ Intersectional analysis therefore allows for a more thorough and nuanced approach to promoting gender equity. Some of the gender questions above speak to how gender interplays with other axes of power and privilege, but it is important to recognise that individual positionalities are often shifting, and in the case of NTDs, very different positionalities may result in the same outcome-lack of access to MDA. Women with caring responsibilities within the home may encounter challenges in making time to come to a central location. Similarly, migrant or nomadic women or men may face particular challenges in accessing MDA, as might those living in fast growing urban informal settlements where MDA programmes have faced more challenges. ${ }^{19}$ 
Table 1 Approaches to Mass Drug Administration (MDA) and why gender matters

\section{Approach to MDA}

House to house

Community drug distributors (CDDs)/ others visit households to register the household members and distribute drugs

Questions for programme managers to consider from a gender perspective

\section{Data sex disaggregated}

Routinely reported data may be sex disaggregated at community level but frequently not cascaded to national level

tot cascaded to national level

- Who is chosen to distribute the drugs and why?

- How are they chosen and who is involved?

- Are they remunerated?

- Does this influence who is involved?

- At what time are drugs distributed?

If it is in the evening is it acceptable/does it prompt security concerns?

- If daytime does this affect the involvement of those who have activities outside the home?

- Who is available within the household and when?

- Does CDD gender effect ability to access to household members or enter the home?

- Does this access also influence individual, household and community adherence?

-Who has the power to decide whether the medicines are taken or not?

- Who has the power to provide consent for household members under the age of 18 years?

- Do power relations at the community level also shape this?

Fixed point approaches: health post clinic/ distribution point Drugs are distributed by CDDs or health workers at a fixed point
Routinely reported data may be sex disaggregated at facility level but frequently not cascaded to national level

- How and to whom is information communicated about the distribution-how does this reflect the needs of migrants, inhabitants of informal settlements, women, men, people of other genders?

- How does it reflect the literacy levels?

-Who is able to attend the distribution? How do livelihoods, gender, power and autonomy affect this?

- Does the location of distribution points influence distribution of medicines, what is the on impact community coverage or the coverage of any specific group within the community?

Child (under 5) health/ special events Particularly common in the African context, drugs are provided within these gatherings
Routinely reported data not disaggregated at national level, with the possible exception of nutrition
- How and to whom is information communicated about the distribution - to what extent does this reflect the needs of women, men, people of other genders migrants, inhabitants of informal settlements?

-Who is able to attend the distribution? How does livelihoods, gender, power and autonomy affect this?

- Who has the power to provide consent for the treatment of those under 18 years of age?

School-based programmes Routinely reported data may Teachers and/or others distribute drugs in the schools

-Who attends school?

- How is this linked to gender and poverty?

- How is informed consent negotiated?

- What happens to those who do not attend school on a be sex disaggregated at school level but frequently not cascaded to national level regular basis?

- What happens to those who drop-out of school/do not complete their primary education?

Coverage improvement
activities
for example, mop up
Additional 'pro-equity'
activities undertaken to
try to ensure everyone is
covered

No sex disaggregated
information and limited

monitoring and provision of MDA to these individuals due to cultural and traditional norms.

Affected individuals can also be hidden within communities due to stigma and lack of perceived need.
For example, in the Nubian Desert area of Sudan, Charles Mackenzie from Liverpool School of Tropical Medicine described how during the distribution of ivermectin, certain nomadic groups do not allow contact between nomad women and girls, and Sudanese health workers distributing the drugs; this presents difficulties in 
For example, in Nigeria people living with disability may be excluded from community level interventions such as house-to-house distribution due to confusion among CDDs regarding how to treat people living with disabilities, particularly when people are unable to stand or perceived to be sick due to their disability. ${ }^{20}$

In addition, disabled people may find the accessibility of fixed distribution points challenging. The involvement of disabled people as CDDs, as a mechanism to increase the involvement and integration of disabled people in community-based interventions, is rarely considered. These examples demonstrate how gender can interact with poverty, (dis)ability, occupation, power, geography and other individual positionalities. We need to think about, and address, multiple interactions if MDA programmes are to be able to rise to the challenge of addressing and promoting equity. Other developments in gender mainstreaming include a critique of the male/ female binary and how this might limit analysis and action to address the needs of people of other genders. Using an intersectional lens to adapt existing gender frameworks to use for NTD programming would allow for a more structured approach to intersectional analysis.

\section{Lesson 3: Gender power and participation-who gets chosen as community representatives and why it matters}

There are many people involved in MDA campaigns and this often varies by disease programme. ${ }^{21}$ CDDs are arguably the backbone of NTD programmes at the community level and include teachers, midwives, nurses and lay people. The rationale behind CDDs is that they are selected by communities through a participatory process, and are trustworthy individuals who are committed to promoting community health. We have become accustomed to the idea that community ownership is an essential element of NTD control, but communities are dynamic with complex power structures that may need better understanding and research in real time. ${ }^{22}$ Lessons from research on community health workers (CHWs) in five African contexts (that may be of relevance and provide lesson learning for the NTD community) show how respondents described several problems related to CHW selection. These included nepotism in the selection process; that the participants willing to undertake the role may not meet selection criteria (eg, older women and men may not meet the educational criteria); the difficulty in recruiting young literate CHWs; early drop out due to misinformation about the job; and too few people volunteering. ${ }^{23}$ The ways in which selection of CDDs is carried out and the extent to which this mirrors or challenges gender norms within NTD programmes is not clear, but arguably the more open and participatory the process, the more chance the process could be gender equitable. Thus, although community participation strategies may look equitable on paper, their implementation is often challenging and can have the unintended consequence of reinforcing gender and social hierarchies within communities.
There are evidence gaps in understanding who CDDs are, by gender and by age. What is clear from the broader literature on CHWs is that gender matters. Naimoli $e t a l^{24}$ state that in many countries, women figure prominently as CHWs although this varies by context and by policy. In Ethiopia, all health extension workers are women and this was found to be positively valued by the community because of the perceived cultural suitability of women handling reproductive health issues. ${ }^{24}{ }^{25}$ Raven $e t a l \mathrm{~s}^{723}$ analysis from exploratory case studies using document reviews, in-depth interviews and focus group discussions shows that in the Democratic Republic of Congo, Senegal, Uganda and Zimbabwe, CHWs were reportedly more likely to be female and aged over 30 years. Older women were seen as being more interested in health issues; already involved in health within families; respected and listened to within communities; and perceived as being able to work easily with people. However, in Ghana, CHWs were more likely to be male as women are more occupied with taking care of their farms, homes and families. ${ }^{23}$ There is need to think critically about who is chosen to be a CDD, what this means for interactions within the community and how they are best supported to deliver on their important role.

\section{Lesson 4: We need to unpack gender and power dynamics at household level}

Gender analysts have long argued that we need to unpack the household and understand the ways in which gender, generation and power play out to affect who can make choices (including to seek healthcare), access resources and take medicines. ${ }^{26}{ }^{27}$ CHWs (such as CDDs) often have to negotiate complex gendered decision-making processes when they visit house to house to deliver MDA.

An example provided at the meeting showed how in Mafia Island in Tanzania, fishermen go to their farms on the mainland (Rufiji) for several months at time, and leave their wives behind with the remaining family feeling unauthorised to make decisions about whether household members were 'allowed to take drugs'. For pregnant women, gendered dynamics were also compounded by fear and lack of certainty as to whether it was safe to take drugs during pregnancy. The pressure to need to 'be pregnant' can give women a negative opinion of a drug that cannot be taken during pregnancy.

CDDs are well placed to understand these gendered dynamics as they are embedded and come from the communities they serve. ${ }^{28}$ As such, they could potentially address the social and cultural norms which can determine health outcomes by acting as agents for social change. ${ }^{28}$ As CDDs may experience the same gender norms and power dynamics as other members of their community, it is important to enhance their critical awareness of these factors and how they have an impact on health. This requires ongoing supportive supervision structures and strategies to enable CDDs to reflect on how they promote gender equity in their work, which 'coverage improvement' strategies will be most appropriate in different 
contexts, including on particularly neglected NTDs such as female genital schistosomiasis. ${ }^{29}$

Parker and Allen's ${ }^{30}$ work on MDA programmes has highlighted the importance of consent and community engagement and how at times community members may feel consent is lacking. ${ }^{30}$ CDDs are a critical bridge between the community and health programmes. ${ }^{31}$ They have underused tacit knowledge about the challenges, opportunities and concerns of different community members with respect to MDA, and how these are shaped by gender and other axes of marginality. Creating forums through which CDDs can share their experiences has the potential to strengthen the responsiveness of NTD programmes and ensure that programmes are adaptable to the realities that community members face. Greater involvement in advising health programmes can also lead to the greater recognition of CDDs and support career advancement and progression, which is particularly important for often underpaid and under-recognised women providers. Furthermore, as the majority of CDDs are unpaid, giving them an opportunity to better understand and feed into MDA processes may increase their motivation and sense of job satisfaction.

\section{Lesson 5: We need to bring a critical gender lens to data at all times}

Lessons from gender mainstreaming include the need to think critically about data, how it is collected, its quality and what it represents. Collecting and using sex disaggregated data to improve the gender equity and responsiveness of NTD programmes, especially at district and community levels, is important. The WHO introduced sex disaggregated reporting forms in 2009. However, how this disaggregated data is reported, collected and used is not always clear. Disaggregated data are rarely found at the national or global level. It is possible that some of the data collected is sex disaggregated at the community level, but this disaggregation is then lost at national level, meaning that important patterns in terms of gender, age and geography are disguised and cannot be acted on. Additionally, collation and aggregation of sex disaggregated at higher levels of the health system may mask gender inequity which is prevalent at local levels, and at specific to certain communities. Participants at the meeting committed to disaggregating by sex and age as the minimum requirement for programmes. However, this commitment could go further by adding questions to coverage evaluation surveys and data quality assessments to provide insights into gender equity. Qualitative and participatory research can also support with better understanding of how gender influences experiences, access to MDA and strategies to document the tacit knowledge of CDDs.

Tanya Wood from the International Federation of AntiLeprosy Associations raised an important concern relating to how data are collected. She provided an example of how leprosy data have been disaggregated demonstrating that in some contexts, more men have leprosy than women and that this has been taken at face value in the figures that are reported by WHO and others. She explained that in reality, women were not showing up in the data because of the multiple challenges they face in accessing care and treatment.

While collecting and disaggregating data is important, the ways these data are collected can make certain groups invisible and this is especially problematic when data are collected at health centres rather than within households at the community level.

\section{CONCLUSION}

In this paper, we have outlined learning from the experiences of 20 years of gender mainstreaming and linked this learning to the MDA activities commonly used as a strategy in the control and elimination of NTDs. We have made the argument that gender matters and needs to be more effectively addressed by the NTD community and more actively incorporated into the development and implementation of NTD programmes. The success of elimination relies on programmes that reach the endemic population and thus effectively break transmission. A 'strategic framing ${ }^{16}$ that could be used to argue for greater gender analysis is that it makes programmes more equitable, but by reducing infection and supporting CDDs, NTD programmes will become efficient and sustainable. The inclusion of gender-informed analysis and action is a win-win situation as it helps to ensure support to and engagement with communities, affected individuals and CDDs. It is important to acknowledge that providing this form of support may increase costs in the short term, but ultimately it could lead to more effective allocation of resources to those most affected. Researchers should develop pathfinding studies to generate more evidence to inform policy frameworks and related guidelines for gender mainstreaming within national NTD programmes. Ultimately, we need to ensure that our approaches do no harm, leave no one behind, ${ }^{6}$ do not exacerbate pre-existing inequalities, and are carried out in an ethically and culturally aware manner. NTD programmes should also rise to the challenge promoting more gender equitable societies. Through the strengthening of the systems that have been developed over the past 30 years to distribute NTD drugs to those living at the 'end of the road', these programmes can be a powerful mechanism for making strides towards achieving universal healthcare: an opportunity that must not be lost.

\section{Author affiliations}

${ }^{1}$ Department of International Public Health, COUNTDOWN Consortium and RiNGs

Consortium, Liverpool School of Tropical Medicine, Liverpool, UK

${ }^{2}$ Department of International Public Health, COUNTDOWN Consortium, Liverpool School of Tropical Medicine, Liverpool, UK

${ }^{3}$ Bill and Melinda Gates Foundation, Seattle, Washington, USA

${ }^{4}$ Department for International Development, London, UK

${ }^{5}$ COUNTDOWN Consortium, Institute for Health Research, University of Health and Allied Sciences, Ho, Ghana

${ }^{6}$ RiNGs Consortium and Pamoja Communications, Brighton, UK

${ }^{7}$ Uniting to Combat NTDs, Brighton, UK 
${ }^{8}$ Department of Parasitology, Liverpool School of Tropical Medicine, Decatur, Georgia, USA

${ }^{9}$ Centre for Neglected Tropical Diseases, Department of Parasitology, Liverpool School of Tropical Medicine, Liverpool, UK

${ }^{10}$ Schistosomiasis Control Initiative, Imperial College London, London, UK

${ }^{11}$ Department of Control of Neglected Tropical Diseases, World Health Organization, Geneva, Switzerland

Acknowledgements We wish to thank the participants and organisers at the 'Neglected Tropical Diseases: Women and Girls in Focus'; meeting held in London, 27-28 July 2016. The COUNTDOWN consortium is a multidisciplinary research consortium dedicated to investigating cost-effective, scaled-up and sustainable solutions, necessary to control and eliminate the seven most common neglected tropical diseases by 2020. COUNTDOWN was formed in 2014 and is funded by UKAID part of the Department for International Development. Thanks also to 'Research in Gender and Ethics: Building Stronger Health Systems' and to Susie Crossman for proofreading the paper.

Contributors All authors (ST, EEM, LD, JJ, CD, MG, KH, TE-P, CM, LAK-H, FMF, PSM) actively contributed to the developing of ideas, through commenting on the paper, sharing tacit knowledge and relevant literature, editing drafts and the final version of this paper. The paper draws in part on discussions from a meeting on women, girls and neglected tropical diseases; JJ, CD, TE-P, FMF, PSM were key organisers of the meeting which was also attended by ST, CM and LAK-H. EM led on synthesising different author inputs, ideas and editing.

Funding This study was funded by Department for International Development (grant no: P06470)

\section{Competing interests None declared.}

Provenance and peer review Not commissioned; externally peer reviewed.

Open Access This is an Open Access article distributed in accordance with the Creative Commons Attribution Non Commercial (CC BY-NC 4.0) license, which permits others to distribute, remix, adapt, build upon this work non-commercially, and license their derivative works on different terms, provided the original work is properly cited and the use is non-commercial. See: http://creativecommons.org/ licenses/by-nc/4.0/

(c) Article author(s) (or their employer(s) unless otherwise stated in the text of the article) 2017. All rights reserved. No commercial use is permitted unless otherwise expressly granted.

\section{REFERENCES}

1. CDC. Neglected Tropical Diseases. 2017 https://www.cdc.gov/ globalhealth/ntd/index.html (cited 3 Aug 2017).

2. Molyneux DH, Savioli L, Engels D. Neglected tropical diseases: progress towards addressing the chronic pandemic. Lancet 2017:389:312-25.

3. Manderson L, Aagaard-Hansen J, Allotey P, et al. Social research on neglected diseases of poverty: continuing and emerging themes. PLoS Negl Trop Dis 2009;3:e332.

4. Hotez P, Ottesen E, Fenwick A, et al. The neglected tropical diseases: the ancient afflictions of stigma and poverty and the prospects for their control and elimination. Adv Exp Med Biol 2006;582:23-33.

5. Hotez PJ, Fenwick A, Savioli L, et al. Rescuing the bottom billion through control of neglected tropical diseases. Lancet 2009;373:1570-5.

6. WHO. Yemen poised to eliminate two debilitating neglected tropical diseases in 2015. $2015 \mathrm{http}: / / w w w . w h o . i n t /$ neglected_diseases/ elimination 2 ntds yemen_2015/en/ (cited 3 Aug 2017).

7. WHO. Investing to overcome the global impact of neglected tropical diseases: third WHO report on neglected diseases. World Health Organization, 2015.

8. Fitzpatrick C, Engels D. Leaving no one behind: a neglected tropical disease indicator and tracers for the sustainable development goals. Int Health 2016;8(Suppl 1):i15-18.

9. Sen G, Ostlin P. Gender inequity in health: why it exists and how we can change it. Glob Public Health 2008;3(Suppl 1):1-12.
10. Morgan R, George A, Ssali S, et al. How to do (or not to do).. gender analysis in health systems research. Health Policy Plan 2016;31:1069-78.

11. Allotey P, Gyapong M. The gender agenda in the control of tropical disease: a review of current evidence, in The gender agenda in the control of tropical disease: a review of current evidence. WHO/TDR, 2005.

12. Larson E, George A, Morgan R, et al. 10 Best resources on... intersectionality with an emphasis on low- and middle-income countries. Health Policy Plan 2016;31:964-9.

13. Rilkoff $\mathrm{H}$, Tukahebwa EM, Fleming FM, et al. Exploring gender dimensions of treatment programmes for neglected tropical diseases in Uganda. PLoS Negl Trop Dis 2013;7:e2312.

14. Uniting to Combat Neglected Tropical Diseases. Neglected Tropical Diseases: Women and Girls in Focus: Summary report of meeting held on July 27-28th, 2016. http://unitingtocombatntds.org/sites/ default/files/document/women_and_girls_in_focus_english.pdf (cited 12 Sep 2017).

15. Hankivsky O. Gender vs. diversity mainstreaming: a preliminary examination of the role and transformative potential of feminist theory. Can J Polit Sci 2005;38:977-1001.

16. Theobald S, Tolhurst R, Elsey H, et al. Engendering the bureaucracy? Challenges and opportunities for mainstreaming gender in ministries of health under sector-wide approaches. Health policy and planning. Health Policy Plan 2005;20:141-9.

17 Tolhurst R, Theobald S. Teaching about gender, health, and communicable disease: experiences and challenges. Gender \& Development 2001;9:74-86.

18. Tolhurst R, Leach B, Price J, et al. Intersectionality and gender mainstreaming in international health: using a feminist participatory action research process to analyse voices and debates from the global south and north. Soc Sci Med 2012;74:1825-32.

19. Krentel A, Fischer PU, Weil GJ. A review of factors that influence individual compliance with mass drug administration for elimination of lymphatic filariasis. PLoS Negl Trop Dis 2013;7:e2447.

20. Hotez PJ, Asojo OA, Adesina AM. A situational analysis of the neglected tropical disease programme in nigeria: a case study of ogun and kaduna states. Liverpool: COUNTDOWN, Liverpool School of Tropical Medicine, 2017.

21. Hotez PJ, Molyneux DH, Fenwick A, et al. Control of neglected tropical diseases. N Engl J Med 2007;357:1018-27.

22. Dean L, Page S, Hawkins $K$, et al. Tailoring mass drug administration to context: implementation research is critical in achieving equitable progress in the control and elimination of helminth neglected tropical diseases in sub-Saharan Africa. Int Health 2016;8:233-4.

23. Raven J, Akweongo P, Baba A, et al. Using a human resource management approach to support community health workers: experiences from five African countries. Hum Resour Health 2015;13:45

24. Naimoli JF, Perry HB, Townsend JW, et al. Strategic partnering to improve community health worker programming and performance: features of a community-health system integrated approach. Hum Resour Health 2015;13:111.

25. Kok MC, Kea AZ, Datiko DG, et al. A qualitative assessment of health extension workers' relationships with the community and health sector in Ethiopia: opportunities for enhancing maternal health performance. Hum Resour Health 2015;13:111.

26. Tolhurst R, Amekudzi YP, Nyonator FK, et al. "He will ask why the child gets sick so often": the gendered dynamics of intra-household bargaining over healthcare for children with fever in the Volta Region of Ghana. Soc Sci Med 2008;66:1106-17.

27. Kamuya DM, Molyneux Catherine S, Theobald S. Gendered negotiations for research participation in community-based studies: implications for health research policy and practice. BMJ Global Health 2017;2:e000320.

28. Theobald S, MacPherson E, McCollum R, et al. Close to community health providers post 2015: Realising their role in responsive health systems and addressing gendered social determinants of health. BMC Proc 2015:9:S8.

29. Gyapong $M$, Theobald $S$. The sexual and reproductive health issue you've probably never heard of.... Open Democracy 2015;50:50.

30. Parker M, Allen T. De-politicizing parasites: reflections on attempts to control the control of neglected tropical diseases. Med Anthropol 2014;33:223-39.

31. Fleming FM, Matovu F, Hansen KS, et al. A mixed methods approach to evaluating community drug distributor performance in the control of neglected tropical diseases. Parasit Vectors 2016;9:345. 